\title{
'I am no man’: a presença feminina no universo nerd e geek
}

DOI: https://doi.org/10.22409/pragmatizes.v12i22.51057

\section{Flávia Lages de Castro ${ }^{1}$ \\ Stephany Lins Pereira ${ }^{2}$ \\ Luiza Carvalho ${ }^{3}$}

\begin{abstract}
Resumo: A cultura nerd e geek vem crescendo cada vez mais nos últimos anos, conquistando seu espaço nas telas, nas páginas e nas lojas, saindo de um contexto de cultura de nicho e se consolidando como mainstream. E com o aumento de sua popularidade, aumenta também a demanda por representatividade não apenas em personagens de suas produções, mas também dentro dos próprios grupos e espaços de fãs e consumidores. Este artigo é parte das pesquisas realizadas pelas autoras e busca dar conta de uma análise da toxidade do comportamento masculino em relação à presença feminina nos fazeres nerds. Assim buscaremos fazer uma breve definição do que é considerado nerd e geek atualmente, entender suas divisões como grupo social, e analisar especialmente a presença feminina no contexto deste universo: como ela é percebida e recebida e quais as dificuldades enfrentadas por mulheres nerds. O título possui referência a uma frase dita no filme O Senhor dos Anéis: O Retorno do Rei (2003).
\end{abstract}

Palavras-chave: cultura nerd, representatividade feminina, identidade, machismo.

\section{'No soy hombre': la presencia femenina en el universo nerd y geek}

Resumen: La cultura nerd y geek sigue creciendo cada vez más en los últimos años, adquiriendo espacio en las pantallas, páginas y tiendas, saliendo de un contexto de cultura de nicho y consolidándose como mainstream. Con el aumento de su popularidad, aumenta la demanda por representatividad no solo en personajes de las producciones sino también en los grupos y espacios de fans y consumidores. Este artículo es parte de las investigaciones realizadas por las autoras y busca dar cuenta de un análisis de la toxicidad del comportamiento masculino en relación a la presencia femenina en los haceres nerds. Así buscaremos establecer una breve definición de lo que es considerado nerd y geek actualmente, entendiendo sus divisiones como grupo social, y analizar especialmente la presencia femenina en el contexto de este universo: cómo es percibida y recibida y cuáles son las dificultades enfrentadas por mujeres nerds. El título del artículo posee referencia a una frase dicha en la película El Señor de los Anillos: El Retorno del Rey (2003).

Palabras clave: cultura nerd; representación femenina; identidad; machismo.

\footnotetext{
${ }^{1}$ Flávia Lages de Castro. Doutora em Sociologia e Direito pela UFF. Professora do Departamento de Arte da Universidade Federal Fluminense, UFF, Niterói/RJ, Brasil. E-mail: flavialages@id.uff.br https://orcid.org/0000-0002-8182-5201

${ }^{2}$ Stephany Lins Pereira. Mestranda em Cultura e Comunicação na Universidade de Lisboa, Portugal. E-mail: stephanylins@id.uff.br - https://orcid.org/0000-0002-9659-5154

${ }^{3}$ Luiza Carvalho. Mestranda em Cultura e Territorialidades na Universidade Federal Fluminense, Brasil. E-mail. ml_carvalho@id.uff.br - https://orcid.org/0000-0002-7465-4213
} 
'I am no man': the female presence in the nerd and geek universe

\begin{abstract}
The nerd and geek culture has been growing constantly each year through movie productions, comic books and in stores, crawling the way out from being a niche culture to mainstream. And with its increasing popularity, so does the demand for representation not only in characters inside the productions but also within its own groups, fandoms and as consumers. This article is part of a series of researches carried out by the authors and seek to present an analysis of the toxic environment created by male behaviour towards the female presence in nerd collectives. Thus, we will seek to make a brief definition of what is considered nerd and geek nowadays, understand its divisions as a social group and analyze especially the female presence in the context of this universe: how it is perceived and received and what are the difficulties faced by nerd women. The title is a reference to a line said in the movie The Lord of the Rings: The Return of the King (2003).
\end{abstract}

Keywords: nerd culture; female representation; identity.

\title{
'I am no man': a presença feminina no universo nerd e geek
}

\section{Introdução}

Inicialmente

considerados

"perdedores" e vistos de uma forma negativa, os nerds foram aos poucos conquistando seu espaço na sociedade, e, com a popularização de seus interesses, ser nerd deixou de ser motivo de constrangimento. Por ter sido, durante muito tempo, um título de um outsider - conceito elaborado por Becker (2008) para definir aqueles que não estão em conformidade com os padrões de comportamento estabelecidos pela sociedade -, era possível inferir que o universo nerd fosse um ambiente acolhedor, sobretudo por seus participantes entenderem as dificuldades de lidar com rejeições e diferenças. Contudo, este não é o caso.
Bourdieu (2012) afirma que uma das formas de manutenção da hegemonia é a recusa da existência legítima e pública de um grupo que reivindica sua visibilidade. Essa é uma das estratégias aplicadas pelos nerds para manter a dominação masculina, branca, cisgênera e heterossexual nas manifestações de seus interesses. Ao recusarem a entrada de mulheres no seu grupo, reafirmam a rejeição que eles próprios sofreram durante muito tempo - e, não raro, radicalizam esse comportamento.

$$
\text { É neste contexto que podemos }
$$
apontar 0 crescimento de uma misoginia $^{4}$ por parte dos homens

\footnotetext{
${ }^{4}$ Ódio, aversão ou preconceito contra mulheres ou performances de gênero ligadas ao feminino.
} 


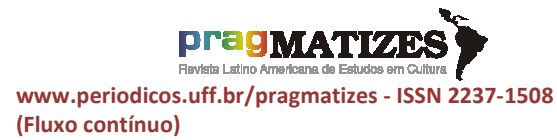
(Fluxo contínuo) nerds, que se utilizam de ataques, ofensas e assédio para afastar as mulheres e tornar 0 ambiente desagradável para elas. Portanto, esse artigo tem como objetivo desnudar parcialmente a cultura nerd, seus múltiplos âmbitos de interesse, analisar a reação à participação feminina nesse universo e tentar entender qual é origem desses discursos de ódio propagados por eles.

Como o universo de interesse desse grupo é vasto, para delimitar nossa análise e realizá-la de forma mais precisa, decidimos por estudar apenas alguns grupos específicos como recorte de pesquisa. Optamos por apresentar exemplos de misoginia em relação às personagens femininas em filmes considerados nerds, em fóruns de discussão, casos dentro da comunidade gamer, e, por fim, em jogos eletrônicos e de tabuleiro. É importante salientar, entretanto, que esta é uma pesquisa em andamento, e que essas são discussões recorrentes levantadas por esse grupo de pesquisadoras, que busca analisar o espaço feminino dentro do universo nerd e geek nas mais diversas instâncias.

\section{O que é ser nerd/geek?}

Essencial é iniciar fazendo uma breve análise sobre o que significa ser nerd e geek, o surgimento das nomenclaturas, as diferenças entre conceitos e as implicações ao redor deles. No geral, os autores de pesquisas no campo (CARVALHO, 2017; LINS, 2017; MATOS, 2014; SILVA, 2014) concordam que a origem do termo é imprecisa. Alguns registros do primeiro uso apontam o livro infantil If I ran the zoo de Dr. Seuss, publicado em 1950, no qual esta palavra era utilizada para designar um estranho ser do zoológico (MATOS, 2014, p. 90). Contudo, a versão que é mais replicada em estudos sobre cultura nerd são dois pressupostos de nascimento do termo relacionado à ciência. $O$ primeiro deles, tem origem no Canadá, onde "um grupo de jovens cientistas passava noites inteiras na divisão de pesquisa e desenvolvimento da Northern Electric, então um atuante laboratório de tecnologia. Mais conhecido pela sigla NERD, ou seja, Northern Electric Research and Development (...)" (MATOS, 2014, p. 20). Outros defendem que o termo surgiu nos Estados Unidos, mais 


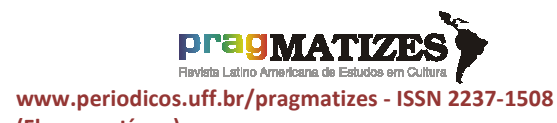
(Fluxo contínuo) precisamente no Massachusetts Institute of Technology - o MIT -, em um momento no qual alguns estudantes apelidavam aqueles que preferiam ficam no instituto estudando ao invés de participar das festas universitárias como knurd - drunk, que significa bêbado em inglês, escrito ao contrário (MATOS, 2011).

A origem do termo, seja ela qual for, carrega consigo uma significação pejorativa. Sua utilização servia para não somente designar um indivíduo que tivesse grande fascínio pelos estudos ou uma inteligência acima da média, mas para designar alguém que, em razão dessas características, enfrentasse dificuldades em estabelecer relações sociais. Por também ter sido associado a um padrão físico, muitas vezes 0 estereótipo do nerd é associado a um homem, branco, esguio, de óculos, aparelho ortodôntico e sem tato social para lidar com mulheres (MATOS, 2014; LINS, 2017). Alguns autores também adicionam ao imaginário criado sobre 0 nerd a forma desajeitada de agir, indiferença sobre o que acontece ao seu redor e ingenuidade (GALVÃO, 2009), um estereótipo reforçado diversas vezes pelo cinema das décadas de 1980 a 2000 , especialmente em obras sobre o ensino médio americano, o high school - como os filmes Clube dos Cinco (1985) e Mulher Nota 1000 (1985), ambos de John Hughes (LINS, 2017, p. 41).

Devido a essa visão pejorativa do rótulo de nerd, e com o avanço da tecnologia após a grande virada eletrônica dos anos 2000, o termo geek começou a ser bastante empregado para tratar de pessoas que poderiam ser consideradas nerds, mas que em vez de focar tanto em estudos e aptidões acadêmicas, fossem mais voltados para os avanços tecnológicos, tais como computadores e videogames, assim como para o consumo de produções de cultura popular massiva - a cultura pop -, tais como "histórias em quadrinhos, filmes, livros e séries que abordam temas de ficção científica, desenhos, jogos eletrônicos e até mesmo de tabuleiro, dentre outros" (CARVALHO, 2017). Para além desse interesse em tecnologia, os geeks eram percebidos como possuidores de maiores habilidades sociais do que os nerds, com maior facilidade de comunicação e carisma (MATOS, 2011). 


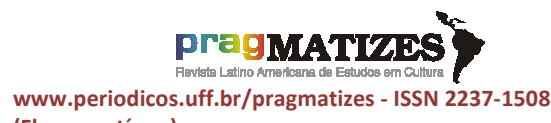
(Fluxo contínuo)
Atualmente, os limites entre nerd e geek são cada vez mais difusos devido à grande influência da tecnologia em nosso cotidiano, e ao apreço de ambos os grupos pela cultura pop, que se torna cada vez mais mainstream. Para fins deste artigo, entendemos nerd e geek como sinônimos, termos pares que designam um grande grupo social.

A identificação como nerd, por permear outras diversas etiquetas sociais que o indivíduo toma para si, tange conceitos apresentados nos trabalhos de Stuart Hall (2006), que defende que as identidades são múltiplas, complexas e fluidas, e que estão sempre em diálogo com fatores internos e externos. Segundo Carvalho (2017), é possível afirmar que a identidade nerd e geek é construída nesse mosaico dentro de um grande espectro de opções nos quais os indivíduos, a partir de observação do que existe como parte da cultura nerd e geek, constrói sua identidade como parte dos nichos presentes nesse grande universo, que pode parecer unificado, mas é bastante diverso.

O consumo é, nesse universo nerd e geek, uma das formas de representação da sua identidade.
Existem, em primeira instância, as disputas simbólicas por legitimação presentes neste âmbito. Essa legitimação vem através não somente das produções consideradas nerds na literatura, cinema e artes - os bens simbólicos, de acordo com Bourdieu (2007) - mas sobretudo de bens materiais, para que esses itens possam ser uma forma, segundo Carvalho (2017, p. 31), "de expressar sua apreciação por determinada produção e mostrar isso para os outros, até mesmo na esperança de encontrar outras pessoas que compartilhem dessa admiração". Ademais, existe um processo de reafirmação presente nesse consumo, uma maneira de se reafirmar como fã.

É importante, aqui, fazer uma apóstrofe para explicar um conceito significativo para o universo nerd e geek: o fã. O autor mais relevante para tratar do assunto é Henry Jenkins, por não apenas estudar 0 que isso significa, mas também por se considerar como tal. O pesquisador se declara como fã e, como um insider, oferece uma pesquisa mais envolvida e engajada com o objeto, na medida em que estuda muitas vezes sua própria vivência. Em razão da origem 


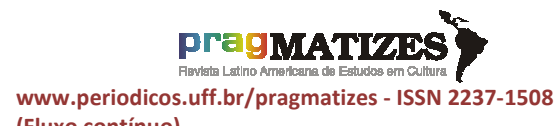
(Fluxo contínuo) do termo, criou-se um imaginário sobre o fã que Jenkins tenta revogar: o termo vem da palavra em latim fanaticum, que tinha relação com devoção a um templo e ser um devoto, também relacionado ao entusiasmo excessivo religioso. (JENKINS, 1992).

O fã, então, era visto como alguém irracional. Segundo o próprio autor, essa concepção mudou, a partir do momento que o fã passou a ser uma parte cada vez mais presente e influenciadora nas produções, no que ele chama de cultura participativa (JENKINS, 2015). O impacto desses admiradores se tornou tão forte que passaram a designar-se como fandom - união das palavras de origem inglesa fan (fã) e kingdom (reino), ou seja, reino dos fãs. Também é possível corresponder a cultura nerd como um fenômeno estudado pelo autor: o media fandom, ou seja, uma cultura que existe na interseção entre a cultura de massa e a vida cotidiana, e que elabora sua identidade e artefatos a partir de textos já presentes no imaginário (JENKINS, 1992, p. 3). E, segundo Matos (2014), essa é a razão para essas conexões intertextuais entre uma enorme variedade de textos midiáticos e não de um gênero ou texto determinado (p. 68), como dito anteriormente sobre esse vasto leque de subgrupos que a cultura nerd abrange.

Em virtude dessa relação profunda dos nerds e geeks com consumo, identidade e legitimidade, o mercado viu uma oportunidade, e se aproveitou dela. É possível, atualmente, encontrar produtos de diversos temas considerados nerds em grandes redes, lojas de departamento e até mesmo em supermercados. Além disso, o mercado de produtos especificamente nerd tem crescido progressivamente nos últimos anos. No Brasil, por exemplo, a venda de licenciamento de produtos - ou seja, os direitos para se utilizar certas marcas para confecção de itens relacionados à cultura nerd gera 18 bilhões por ano, segundo a Associação Brasileira de Licenciamento (ABRAL), um crescimento de $50 \%$ nos últimos cinco anos.

Outro fator que exemplifica essa relação com o consumo e também com o fato do nerd estar se tornando cada vez mais "descolado" - nos termos de Matos (2014) - é o cinema. Atualmente, entre as dez maiores 


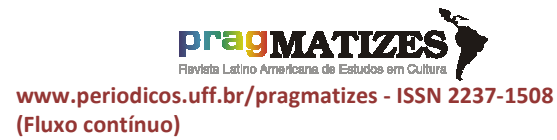

(Fluxo contínuo) bilheterias do mundo ${ }^{5}$, seis desses filmes são considerados narrativas da cultura pop, apreciadas pelo público nerd e geek - Os Vingadores (2012), em 8우 Jurassic World (2015) em 6우 Vingadores: Guerra Infinita (2018) em 5o; Star Wars - O Despertar da Força (2015) em 4ㅇ; Avatar (2009), em 2o; e Vingadores: Ultimato (2019) em 1‥ Ou seja, o impacto cinematográfico das narrativas desse estilo é percebido por serem produzidos diversos filmes com alta lucratividade, especialmente com a grande popularidade do Universo Cinematográfico da Marvel e a sua culminância nos filmes dos Vingadores, que ocupam três posições nessa lista. É importante citar que Vingadores: Ultimato (2019), ultrapassou Avatar (2009) que permaneceu no topo desta lista por quase dez anos.

Assim, conclui-se que essa tríade - consumo, identidade e representatividade - é, de fato, pertinente quando se trata de pesquisa sobre cultura nerd e geek. Apesar de múltiplo, o consumo é uma forma de

\footnotetext{
${ }^{5}$ De acordo com levantamento atualizado no ano de 2021. Disponível em: https://www.tecmundo.com.br/culturageek/210429-10-maiores-bilheterias-todostempos-cinema.htm. Acesso em: 30/04/2021
}

reafirmar seus interesses, e pode gerar identificação por outrem, o que fortalece a confluência como um grupo. Foi possível perceber, também, que o nerd tem se tornado foco do mercado, em razão dessa construção identitária ser pautada pelo consumo. O nerd e o geek são consumidores ávidos e utilizam-se de seu capital simbólico para reafirmar seu papel de fã entre indivíduos e também validar seu espaço e poder perante outras subculturas.

\section{Uma cultura múltipla: os nichos presentes no universo nerd e geek}

Embora a considerada "cultura nerd" seja vista como um grande universo abrangente, é importante frisar que os que se identificam como nerds e geeks nem sempre têm os mesmos gostos e opiniões. O universo nerd é uma espécie de guarda-chuva, que abriga diversas comunidades e nichos com interesses diversos. É possível que uma pessoa que se considera nerd seja parte de diversos grupos dentro desta cultura, ou que participe ativamente de apenas um, e nenhuma dessas opções o tornaria mais ou menos nerd (CARVALHO, 2017). 


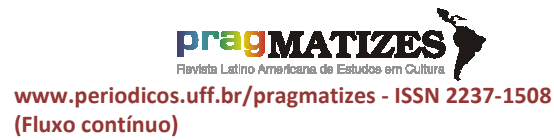

Para citar alguns exemplos que serão trabalhados mais adiante, podemos destacar os aficionados em cultura pop, especialmente os universos de histórias em quadrinhos, super-heróis, filmes e séries de ficção científica e grandes sagas épicas. E nesse contexto, a ideia de fandom trabalhada por Jenkins (1992) é essencial, visto que há uma grande variedade de gêneros, estilos e empresas que são responsáveis por essas produções. Dentre as mais populares podemos destacar a Marvel e a $D C$ Comics, que produzem conteúdos de quadrinhos, super-heróis e suas adaptações, nas mais diversas plataformas. Há também a saga Star Wars da LucasFilm, as histórias de J. R. R. Tolkien - em especial O Senhor dos Anéis e $O$ Hobbit -, a série britânica Doctor Who, as histórias do universo de Star Trek, e diversas outras produções.

Há também os chamados otakus, que em seu contexto original era um termo usado para designar os jovens japoneses que "preferem isolarse em um mundo virtual, onde imperam os comics e mangás (...), as bonecas barbies e os desenhos animados, os games, a internet e o mundo pop" (ENNE, 2006), mas que no atual contexto nacional se entende como os que apreciam a cultura pop japonesa, especialmente suas histórias em quadrinhos e desenhos animados, chamados respectivamente de mangás e animes.

Outra grande porção da comunidade nerd é constituída pelos entusiastas de jogos, e neste contexto podemos destacar especialmente três categorias: jogos eletrônicos, jogos de tabuleiro e jogos de interpretação de papéis.

Em relação aos jogos eletrônicos, os videogames, temos os jogos dos mais diversos gêneros elaborados para consoles ou computador, que podem ser jogados individualmente ou em grupo e que geram constantes debates e trocas entre seus apreciadores. Uma prática comum atualmente para os gamers é a de fazer transmissões de suas sessões de jogos - chamadas de streams - para que eles possam comentar sobre suas partidas enquanto jogam.

Os jogos de tabuleiro são assim denominados com base nos jogos nos quais existe um quadro ou placa de base, e a partida acontece em cima 


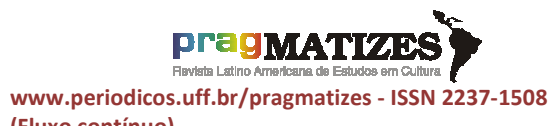
(Fluxo contínuo) dele, com base em percursos, objetivos ou desafios. Porém, atualmente o termo é amplamente utilizado, "abrangendo jogos que se jogam sobre uma mesa, mesmo os que não têm tabuleiros propriamente ditos - como os jogos de cartas tradicionais e os muitos jogos de cartas modernos" (DUARTE, 2012). É bastante comum a prática de colecionar jogos, e existem até mesmo locais específicos para locação dos mesmos - chamadas ludotecas - e restaurantes que se propõe a disponibilizar jogos para seus clientes pelo tempo em que estiverem no local.

Já os jogos de interpretação de papéis, os chamados RPGs ${ }^{6}$, trabalham um aspecto mais lúdico. Neles, é necessário que cada jogador crie uma ficha de personagem, contendo todas as informações sobre - mesmo. Após a criação dos personagens, o mestre do jogo os conduz por uma história na qual suas decisões serão tomadas e a eficácia de suas ações é determinada de forma aleatória através de rolagens de dados, definindo se obteve sucesso ou fracasso em seu objetivo, dependendo

\footnotetext{
${ }^{6}$ Abreviação do termo em inglês Role Playing Game.
}

do sistema em que o jogo é ambientado. Chamamos de sistema o modo de jogo, que determina o contexto no qual os jogadores estão inseridos e a aventura será realizada. Cada sistema contém as regras que regem a lógica do jogo (LINS, 2017) e do mundo no qual ele se ambienta. Eles podem variar de aventuras medievais e épicas, a histórias futuristas ou distópicas.

Desta maneira, é possível perceber que embora exista uma ideia de generalização da cultura nerd, ela é extremamente ampla, e possui diversas vertentes dos mais variados assuntos, temas e gêneros narrativos. Mas apesar de tantos espaços e nichos dentro deste universo, na maioria deles um denominador comum é perceptível: a presença feminina pode causar incômodos e reclamações.

\section{“Menina não entra!": o machismo e suas implicações}

Como mencionado, o aumento das possibilidades de consumo e a ampliação dos contatos através das tecnologias digitais redundaram num crescimento deste grupo de interesses 


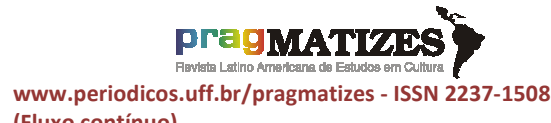
(Fluxo contínuo) comuns. Não é de estranhar, portanto, que a participação feminina neste nicho tenha crescido o suficiente para criar algumas situações que no passado eram inimagináveis. Se antes era um espaço ocupado por pessoas que, sofrendo pressões sociais, se juntavam entre semelhantes até como forma de reforço de identidade e gostos, agora o reforço permanece e, como ser nerd caiu no "mainstream e no que se considera cool" (TOCCI, 2009), a popularização redundou em uma necessidade destes grupos estabelecerem fronteiras de forma rotineira e, algumas vezes, agressiva. No sentido acima indicado temos provas quotidianas de validação e revalidação de pertencimento destes grupos em contatos sociais mediados ou não por computadores e smartphones.

Tendo sido um "Clube do Bolinha"7 por muito tempo, o lugar de meninos e nunca de meninas, que ali só entravam em seus sonhos,

\footnotetext{
${ }^{7}$ Bolinha é um personagem das histórias de Luluzinha, uma série de histórias em quadrinhos e desenhos animados baseados na personagem homônima criada pela cartunista Marjorie Henderson Buell no ano de 1935. Ele era o líder do clube dos meninos que possuía o lema: "Menina não entra!", que dá o título a este item.
}

percebe-se com força desproporcional - para os avanços sociais e de respeito mútuo e de diversidade que temos nos esforçado para ter nos dias de hoje - o estranhamento dos coletivos que podem ser rotulados nerds com figuras femininas.

Essa "revolução nerd" acabou
gerando rivalidades entre os
diversos tipos de apreciadores da
cultura pop. Antes um grupo
unido, a comunidade nerd agora
se compartimentaliza em diversas
tribos, gerando um ambiente
tóxico, rancoroso e
preconceituoso. Um dos grupos
que mais sofre preconceito dentro
da comunidade nerd é o das
mulheres. (MESQUITA, 2018)

Então se considera: uma sociedade machista beirando a misoginia, um grupo que tornou-se tóxico com o tempo, e uma participação mais efetiva do público feminino no nicho anteriormente masculino contabilizado em 2016 (PUIG, 2018) mostrando que a participação feminina em games no Brasil era de 52\%, e nos E.U.A. 43\% dos consumidores de quadrinhos eram mulheres. Com isso, não é incomum que a misoginia se torne explícita no anonimato e seja justificada pelos desejos dos próprios interlocutores - 0 que a psicologia chama de inversão de 
CASTRO, Flávia Lages de; PEREIRA, Stephany Lins; CARVALHO, Luiza. ‘I am no man': a presença feminina no universo nerd e geek. PragMATIZES - Revista Latino-Americana de Estudos em Cultura, Niterói/RJ, Ano 12, n. 22, p. 425-442, mar. 2022.

culpa. Neste sentido, o que mulheres sofrem com o machismo é considerado culpa delas mesmas.

Imagem 1 - Culpabilização da vítima. ${ }^{8}$

Anônimo disse...

Vocês nos reprimiam na década de 90 . Nos chamavam de virjões, mandava a gente crescer. Nerds e gamers sempre foram desprezados pelas mulheres. Por que vocês querem que as aceitemos agora????

13 DE JULHO DE $201813: 33$

É então comum que as mulheres sejam tratadas como não pertencentes a este mundo de nerds que, pela definição de alguns, é masculino exclusivamente. Também há as críticas às mulheres que não apenas consomem, mas buscam por uma melhor representatividade dentro das produções, que são chamadas de "lacradoras", em referência ao jargão popular que significa "arrasar", mas que neste sentido assume uma conotação de deboche, insinuando que elas só buscam essa representatividade para aparecer $\mathrm{e}$ tomar o lugar masculino.

\footnotetext{
${ }^{8}$ Comentário encontrado em https://escrevalolaescreva.blogspot.com/2018/ 07/misoginia-vinganca-dos-nerds.html
}

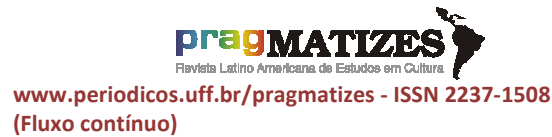

Imagem 2 - Comentário afirmando que mulheres não pertencem à cultura nerd. ${ }^{9}$

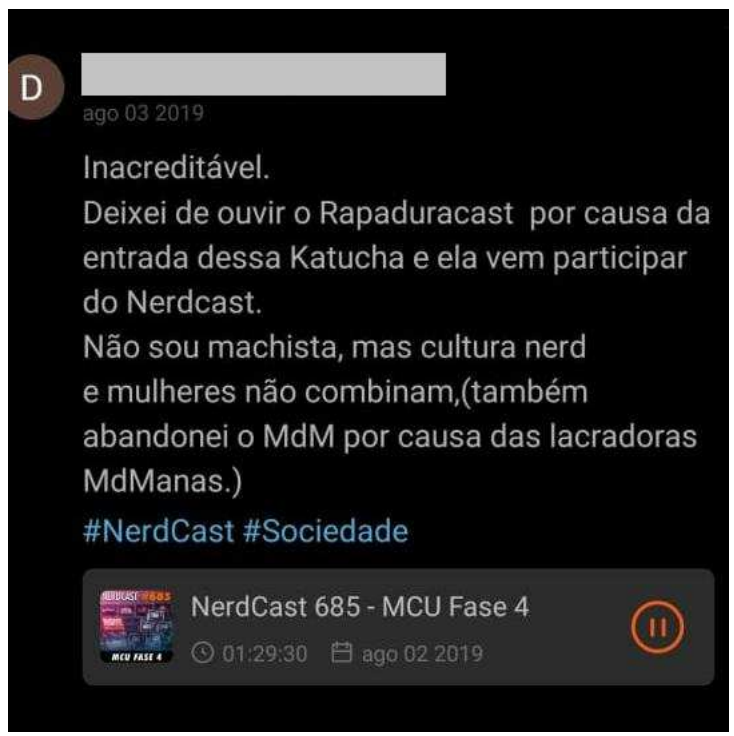

Ao considerarmos que os limites do "ser nerd" passam pelo consumo, sendo um fenômeno inserido no capitalismo, a questão que se traz à baila é: quem é o sujeito, o alvo destas produções/objetos de consumo. ${ }^{10}$ Observando os exemplos apresentados, não resta dúvida que este sujeito é homem, branco, heterossexual e cisgênero, enquanto as mulheres apenas existem nesse meio para dar sentido aos desejos e

\footnotetext{
${ }^{9}$ Comentário de 03.08.2019 no Blog Jovem Nerd: https://www.jovemnerd.com.br.

${ }^{10}$ Conforme já discutido em CASTRO, F. L. A arte dos quadrinhos e a Comic Con 2018: uma análise da participação feminina. XV Enecult encontro de estudos multidisciplinares em cultura. Disponível em:

http://www.xvenecult.ufba.br/modulos/submiss ao/Upload-484/111624.pdf. Acesso em: 30 set. 2019.
} 


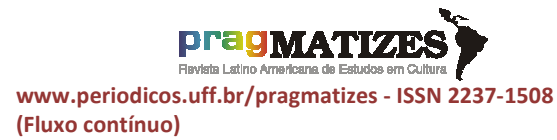
(Fluxo contínuo) ideais do mesmo, mas nunca como suas pares, o que Laura Mulvey chama de Male Gaze.

A mulher, desta forma, existe na cultura patriarcal como 0 significante do outro masculino, presa por uma ordem simbólica na qual o homem pode exprimir suas fantasias e obsessões através do comando lingüístico, impondo-as sobre a imagem silenciosa da mulher, ainda presa a seu lugar como portadora de significado e não produtora de significado. (MULVEY, 2008, p. 7).

A figura feminina usada como chamariz para o público é uma prática comum, pois a sua presença auxilia no objetivo de obter boas bilheterias. Um estudo divulgado em $2018^{11}$, baseado em 350 das melhores bilheterias no cinema mundial de 2014 a 2017 indica que do total, 105 tiveram protagonistas mulheres e 245 homens, e a média entre investimento e bilheteria apontou um lucro mais robusto em filmes protagonizados por mulheres. Não obstante, o protagonismo não é o único indicativo que importa para nossa análise. O estudo acima indicado tomou os filmes cujas atrizes são as principais em detrimento dos homens e os fez passar pelo Bechdel

\footnotetext{
${ }^{11}$ Disponível em: https://shift7.com/mediaresearch
}

Test $^{12}$, que consiste em considerar três elementos: possuir duas ou mais personagens femininas com nomes e espaço na história, e a existência de um diálogo entre mulheres sobre algo que não sejam homens. Daí supomos estar o incômodo de alguns indivíduos do sexo masculino acostumados com a naturalização do protagonismo masculino.

Os filmes para o público nerd, entretanto, encontram muita resistência - do público masculino quanto a feminilização das produções cinematográficas. Cada vez que uma produção de cinema ou de TV traz protagonistas mulheres, vê-se uma enxurrada de lamúrias e oposição nas redes sociais, notadamente nas brasileiras. As reclamações são maiores e mais frequentes em casos de produções consagradas e/ou que possuíssem elencos majoritariamente masculinos, como é o caso da saga Star Wars, criada pelo cineasta George Lucas. Em 2015 foi anunciado o retorno da franquia, após 10 anos de seu último lançamento, com o filme $\mathrm{O}$ Despertar da Força, trazendo uma

\footnotetext{
12 Pode-se conferir uma lista de filmes que passaram por este crivo em https://bechdeltest.com/.
} 


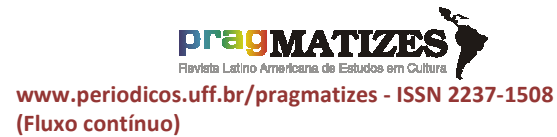
(Fluxo contínuo) personagem feminina como protagonista, o que causou muitas reclamações de fãs antigos da saga. Em 2016 foi lançado mais um filme, Rogue One: Uma História Star Wars, que novamente apresentou uma protagonista feminina, causando uma nova leva de contestações pela escolha de protagonista, como exemplificamos abaixo:

Imagem 3 - comentários do facebook (https://facebook.com/) no lançamento de Rogue One: Uma História Star Wars

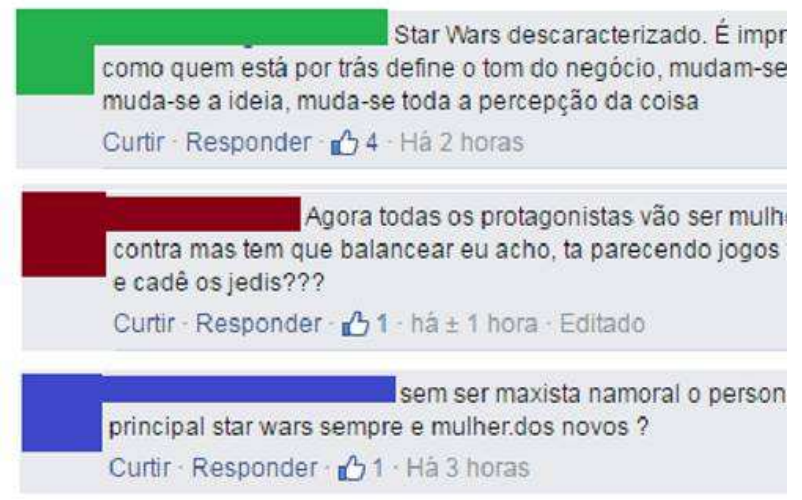

E não é apenas nos papéis de protagonismo que a presença feminina causa incômodo, ocasionalmente uma simples cena pode causar estranhamento ou dificuldade de aceitação, como é o caso da cena cuja fala dá título a este artigo. A cena em questão é parte do filme O Senhor dos Anéis: O Retorno do Rei (2003), na qual o Rei Bruxo de Angmar se gaba de que enfrentá-lo é inútil pois existe uma profecia que afirma que nenhum homem mortal poderá matá-lo (como dito pelo próprio personagem no filme: "Seu tolo, nenhum homem pode me matar."), e com isso a personagem Éowyn tira seu capacete e diz "I am no man" - "Eu não sou um homem", em tradução livre -, e consegue golpeá-lo, culminando em sua morte. A cena tornou-se clássica para a saga, e extremamente significante, especialmente para mulheres que gostam da história. Entretanto, existe uma postagem no site Reddit, um fórum online, na qual um usuário afirma que considera a cena simples demais:

A cena próxima ao fim da trilogia onde a garota estava falando com o Rei Bruxo e ele disse 'Nenhum homem pode me matar', e ela foi toda "mas eu não sou homem" e então matou o Rei, foi meio brega pra mim. (...) Por favor, notem que eu não li os livros (embora ainda planeje ler), e se existe alguma coisa que eu esteja perdendo por ter só assistido os filmes, estou aberto a novas ideias. Acredite, se eu estou falhando em ver algo e não é só o fato de ela ser mulher que permite que ela mate 0 Rei Bruxo, eu aceitaria no mesmo instante e mudaria completamente minha visão sobre a cena. Só pareceu 
CASTRO, Flávia Lages de; PEREIRA, Stephany Lins; CARVALHO, Luiza. ‘I am no man': a presença feminina no universo nerd e geek. PragMATIZES - Revista Latino-Americana de Estudos em Cultura, Niterói/RJ, Ano 12, n. 22, p. 425-442, mar. 2022.

meio...simples demais pra mim (REDDIT, 2012.) ${ }^{13}$.

Em jogos eletrônicos, dada a extensão das possibilidades de análise do sexismo nestes, são apresentados dois casos relevantes para que se possa ter ideia da toxicidade masculina neste meio. Tendo início em 2014 após uma desenvolvedora de jogos ser acusada de estar se relacionando com jornalistas para conseguir boas resenhas, 0 Gamergate foi um movimento de ódio contra o desenvolvedor que espalhouse principalmente para mulheres com ataques misóginos e devastadores.

Na prática, o Gamergate investiu muito mais no ataque principalmente misógino, mas também homofóbico, transfóbico e racista a trabalhadoras/es da indústria, crítica e demais membros da cultura de jogos digitais (BURGESS; METAMORO - FERNANDÉZ, 2016). Suas principais vítimas, além de Zoë Quinn, foram a crítica feminista de jogos Anita Sarkeesian e a game designer Brianna Wu. Enquanto ambas sofreram as mesmas ameaças e vazamento de informações de Quinn, Sarkeesian teve cancelar uma palestra que daria na Utah State University por essa sofrer uma ameaça de tiroteio em massa

\footnotetext{
${ }^{13}$ Tradução própria. O comentário original em inglês pode ser encontrado em https://www.reddit.com/r/lotr/comments/128qc3 /the_whole_i_am_no_man_line/
}

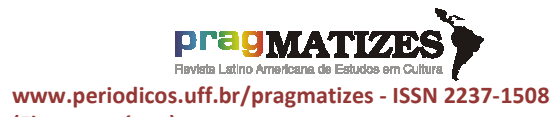
(Fluxo contínuo)

(AHMED; MARCO, 2014), enquanto Wu teve de fugir de sua casa após receber ameaças de estupro citando seu endereço residencial - algo que também aconteceu com seus parentes próximos (TOTLO, 2014). (GOULART; NARDI, 2017, p. 255)

Em um exemplo mais recente, em setembro de 2020 a jogadora brasileira Isadora Basile estreou como apresentadora do canal da marca Xbox no Youtube. Apenas um mês depois, em outubro, ela anunciou que desde que começou seu trabalho, estava sendo criticada por não jogar determinados jogos e que por isso ela não seria "digna" de seu cargo, além de estar recebendo diversas ameaças de morte e estupro, e sofrendo perseguição em suas redes sociais, e por isso havia sido desligada do cargo pela Microsoft, para evitar sua exposição a esse tipo de assédio ${ }^{14}$.

No mundo dos jogos de tabuleiro para jovens e adultos não é diferente $^{15}$. Em entrevista com 0

\footnotetext{
${ }^{14}$ Matéria sobre o caso disponível em: https://www.uol.com.br/start/ultimasnoticias/2020/10/16/microsoft-demiteapresentadora-apos-assedio-e-ameaca-demorte.htm. Acesso em: 30/04/2020.

${ }^{15}$ Não estamos contando aqui também jogos infantis que partem de uma divisão de gênero contundente.
} 
produtor de conteúdo e colecionador de jogos Átila Kawauti, dono de mais de trezentos jogos, ele afirmou que jogos estadunidenses não apresentam muitos personagens femininos e estes, quando muito, perfazem menos de $20 \%$ do elenco. Kawauti tem predileção por jogos com miniaturas a serem pintadas e estas são, geralmente com temática medieval que, a exemplo de produções como Senhor dos Anéis e Game of Thrones, a participação feminina é pífia e muitas vezes sexualizada.

Imagem 5 - Jogos de tabuleiro adulto/juvenis mais vendidos em 2020/2021 e relação personagens masculinos e femininos'.

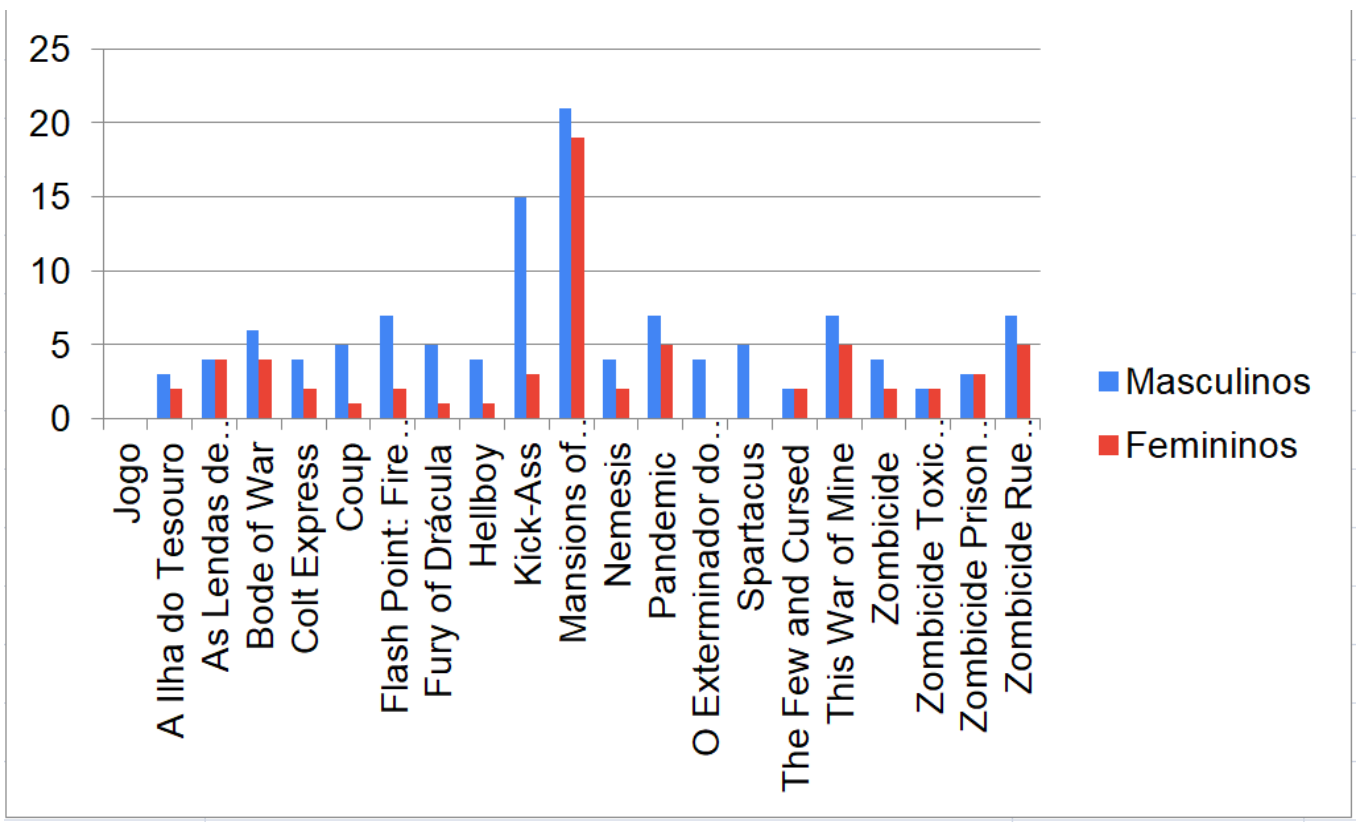

Rotiroti indica que somente dois jogos de tabuleiro nos catálogos de jogos vendidos no Brasil têm como protagonista única uma personagem feminina: 
Cleópatra e The Few and Cursed. Mas ele também afirma que jogos bastante vendidos nos últimos anos como Zombicide, Mansions of Madness, Kick-Ass e Nemesis não têm exatamente um protagonista possui um certo equilíbrio entre os personagens masculinos e femininos". 


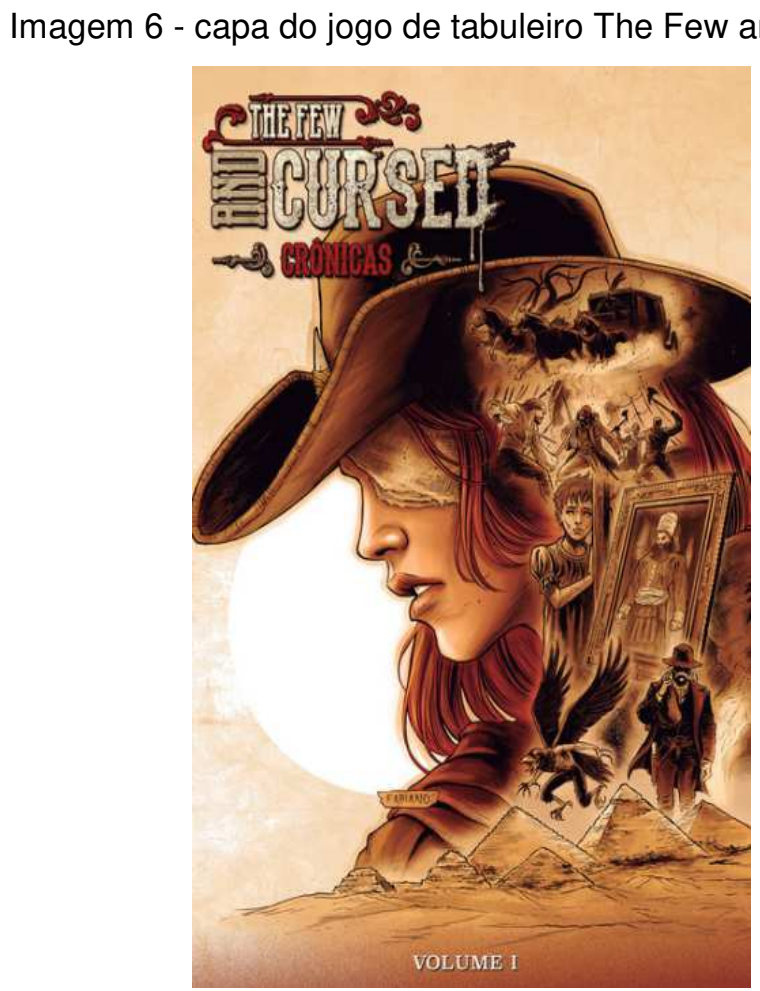

Jogos de tabuleiros infantis, em geral não enquadrados como objeto de desejo de nerds, carregam um sexismo ainda mais aparente em cores e temas. Para meninas, princesas e muito rosa e lilás. Para meninos, ação e tons de azul. 0 problema é que as meninas estão crescendo querendo a ação, e os meninos estão considerando este fato uma invasão de "seu" território, por terem sido ensinados de que aquele espaço é apenas deles.

\section{Conclusão}

Muito da identidade Nerd/geek passa pelo consumo, conforme já elencado neste artigo, dando a estudiosas e estudiosos desta expressão pública de identidade uma gama bastante grande de meios para estudo de seu objeto. Assim temos consciência que o escopo deste artigo não poderia dar conta de tão variadas possibilidades; entretanto, é um ponto de partida para um debate necessário de uma pesquisa que cada vez mais se mostra relevante.

Percebe-se, portanto, que considerando "mundo" nerd no que mais este admira, ele é um algo feito para homens e, não obstante termos mudanças acontecendo, a resistência que ainda existe a elas tem sido bastante nociva a 
mulheres. A rejeição ao gênero feminino apenas atrasa, mas não impede a entrada cada vez mais notável das mulheres nesse grupo.

Finalmente, sabemos que para os que vendem os produtos nerds - filmes, jogos, camisetas etc. - o público interessante é aquele que compra, não importando seu gênero. Prevemos então que a reação tóxica masculina a longo prazo não surtirá o efeito desejado e por este motivo temos elaborado através desta pesquisa ramificações em estudos acerca da presença das mulheres no mundo nerd.

\section{Referências bibliográficas}

BECKER, Howard. Outsiders: estudos de sociologia do desvio. São Paulo: Editora Schwarcz-Companhia das Letras, 2008.

BOURDIEU, Pierre. A distinção: crítica social do julgamento. São Paulo: Edusp; Porto Alegre: Zouk, 2007.

BOURDIEU, Pierre. A dominação masculina. Rio de Janeiro: Bertrand Brasil, 2012.

CARVALHO, Luiza. Identidade e representação dos fãs de cultura nerd/geek: analisando a comic con experience. (Monografia de graduação em Produção Cultural). Universidade Federal Fluminense, Niterói, 2017.

DUARTE, Luiz Cláudio. Jogos de Tabuleiro no Design de Jogos Digitais. XI SBGames, Brasília, 2 a 4 de novembro de 2012.

ENNE, Ana Lucia Silva. À perplexidade, a complexidade: a relação entre consumo e identidade nas sociedades contemporâneas. Comunicação, mídia e consumo. São Paulo, vol. 3, n.7 p. 11-29. Jul. 2006

GALVÃO, Danielle Pini. Os nerds ganham poder e invadem a TV.Intr@ aciência, Uniesp, p. 34-41, 2009.

GOULART, Lucas; NARDI, Henrique. Gamergate: cultura dos jogos digitais e a identidade gamer masculina. Revista Mídia e Cotidiano, Niterói, v. 11, n. 13, p. 250268, dez. 2017.

HALL, Stuart. A identidade cultural na pós-modernidade. Rio de Janeiro: DP\&A, 2006.

JENKINS, Henry. Textual poachers: Television fans and participatory culture. New York ; London: Routledge, 1992.

JENKINS, Henry. Cultura da convergência. São Paulo: Aleph, 2015

LINS, Stephany. Meu cosplay, minhas regras: uma análise sobre o cosplay feminino e do espaço da mulher no universo nerd e geek. (Monografia de graduação em Produção Cultural). Universidade Federal Fluminense, Niterói, 2017.

MATOS, Patrícia. O nerd virou cool: consumo, estilo de vida e identidade em uma cultura juvenil em ascensão. (Mestrado em Comunicação). Universidade Federal Fluminense, Niterói, 2014. 
MATOS, Patrícia. O nerd virou cool: identidade, consumo midiático e capital simbólico em uma cultura juvenil em ascensão. XVI Congresso de Ciências da Comunicação na Região Sudeste-Intercom, 2011.

MESQUITA, B. Por que o mundo nerd é machista? Disponível em: http://farofageek.com.br/videos/por-que-o-mundo-nerd-e-machista/. Acesso em: 12. jun. 2020.

MULVEY, Laura. Visual Pleasure and Narrative Cinema. Berlin: Grin Verlag, 2008.

POLLITT, Katha. The Smurfette Principle. The New York Times Magazine, 1991. Disponível em: https://www.nytimes.com/1991/04/07/magazine/hers-the-smurfetteprinciple.html.

PUIG, Rebeca dos Santos. Machismo e 'orgulho nerd': o que temos para comemorar? Disponível em: https://www.comunicaquemuda.com.br/orgulho-nerd-emachismo/ Acesso em: 30 nov. 2018.

TOCCI, J. Geek cultures: media and identity in the digital age. 2009. 449 f. Dissertação (PhD em Comunicação). University of Pennsylvania, Philadelphia, 2009. 